\title{
Factors associated with skin and soft tissue infections among people who inject drugs in the United Kingdom: A comparative examination of data from
} two surveys

\author{
Jason Doran $^{\mathrm{a}, \mathrm{b}}$, Magdalena Harris ${ }^{\mathrm{a}, *}$, Vivian D. Hope ${ }^{\mathrm{b}, \mathrm{c}}$, Talen Wright ${ }^{\mathrm{a}}$, Claire Edmundson ${ }^{\mathrm{b}}$, \\ Katy Sinka ${ }^{\mathrm{b}}$, Ellen Heinsbroek ${ }^{\mathrm{b}}$ \\ ${ }^{a}$ Social and Environmental Health Research, London School of Hygiene and Tropical Medicine, London, United Kingdom \\ ${ }^{\mathrm{b}}$ National Infection Service, Public Health England, London, United Kingdom \\ ${ }^{\mathrm{c}}$ Public Health Institute, Liverpool John Moore's University, Liverpool, United Kingdom
}

\section{A R T I C L E I N F O}

\section{Keywords:}

People who inject drugs

Skin and soft tissue infections

Bacterial infections

Injection-site infections

Vein damage

Abscesses

Harm reduction

\begin{abstract}
A B S T R A C T
Background: People who inject drugs (PWID) are at high risk of injection-related skin and soft tissue infections (SSTI). If not treated promptly, these can lead to serious health complications, which are a considerable healthcare burden. Data from two community surveys, with different approaches, were used to assess SSTI prevalence and associated factors among PWID to inform intervention implementation.

Methods: Data were analysed from two surveys, a national surveillance survey $(\mathrm{n}=2,874 ; 2017-18)$ of infections among PWID in the United Kingdom (UK) and an in-depth survey ( $n=455 ; 2018-19)$ of SSTI among PWID based in London, UK. Multivariable logistic regression models were constructed to ascertain the factors associated with self-reported SSTI.

Results: High prevalence of SSTI were reported in both samples: $52 \%$ of participants from the national surveillance survey reported having SSTI within the preceding 12 months and $65 \%$ of the London sample reported a lifetime history of SSTI. The factors associated with SSTI in both surveys were similar, including older age; number of years injecting; number of attempts required to inject into the vein; injecting into the hands, feet, groin or neck and re-using or sharing needles/syringes.

Conclusions: The number of PWID reporting SSTI in the UK is concerningly high. The two surveys used different recruitment approaches but found similar associations. We provide strong evidence of a relationship between venous access difficulty and SSTI. To stem the increase of SSTI and related complications in the UK, it is crucial that interventions attend to the underlying causes of venous damage among PWID.
\end{abstract}

\section{Introduction}

People who inject drugs (PWID) constitute an extremely vulnerable population with high levels of morbidity and premature mortality. Skin and soft tissue infections (SSTI) disproportionally affect PWID with global lifetime prevalence estimates ranging from $6 \%$ in Australia, through $27 \%$ in the USA to $69 \%$ in Ireland (Larney et al., 2017; Maloney, 2010; Salmon, 2009). They are also a common factor leading to hospitalisation, for example, a study found SSTI accounted for $64 \%$ of infections among PWID admitted to a hospital in Miami, USA (Tookes et al., 2015). Despite the high global prevalence of SSTI, public health policy and associated harm reduction interventions for PWID have largely focused on preventing overdoses, and on the prevention and treatment of blood borne viruses (Boucher et al., 2017), with elimination targets in place for viral hepatitis and HIV (UNAIDS, 2017; World Health Organisation, 2016). The development of associated prevention and treatment interventions have been comparatively neglected.

Bacterial SSTI in PWID have been increasing in the UK since 2012/ 13 , with yearly increases in hospital admission data reported, especially in those aged 45-55 years old (18\% increase in admissions per year) (Lewer et al., 2017). Laboratory surveillance of methicillin-sensitive and methicillin-resistant Staphylococcus aureus (MSSA/MRSA) and Group A streptococci (GAS), common bacteria found in SSTI, has also shown a spike in infections (Public Health England, 2019a). Several outbreaks of GAS and MRSA have been reported in England, with a

\footnotetext{
* Corresponding author.

E-mail addresses: doranja@tcd.ie (J. Doran), Magdalena.harris@lshtm.ac.uk (M. Harris).
} 
large number of cases reported in prisons, among the street homeless and/or PWID (Bundle et al., 2017; Kwiatkowska et al., 2018; Packer et al., 2019; Public Health England, 2019a). The cause of the recent increase in SSTI is not clear but is likely to be multifactorial, with possible factors including an aging cohort of PWID, the impact of austerity on services, increased homelessness, and changes in drug use (Harris et al., 2020; Public Health England, 2019a)

Bacterial SSTI in PWID are most commonly found on the arms, legs, buttocks or groin, corresponding to common drug injection sites (Hope et al., 2008). SSTI are often characterised by the presence of pus (specific to abscesses) or tenderness, swelling and redness (cellulitis). In addition, poor vein health as a consequence of injecting drug use can lead to chronic ulceration, particularly on the legs, which significantly impact on PWID mobility and quality of life (Hope, 2010). PWID experience multiple barriers to care access, such as lack of material resources, reluctance to disclose drug use, competing priorities and stigma (Miller Lloyd et al., 2020; Neale et al., 2008), with many selftreating their infections and/or delaying treatment seeking (Gilbert et al., 2019; Roose, 2009). This can result in increased disease severity and prolonged inpatient hospitalisation (Gilbert et al., 2019). Complications associated with chronic or severe SSTI include septic arthritis, septicaemia, osteomyelitis, endocarditis and AA amyloidosis (del Giudice, 2004; Harris et al., 2018). High levels of hospital admissions as a result of SSTI complications place an unnecessary burden on health care services; estimates of costs to the NHS are in the region of $£ 77$ million per annum (Marks et al., 2013).

Given the significant and increasing personal and healthcare burden of injecting-related SSTI, there is urgent need to develop acceptable, accessible and effective preventative interventions. Understanding the factors associated with SSTI among PWID in the UK is crucial to inform understanding of the rise in infections and implement effective interventions. Factors associated with SSTI are geographically variable, given geographical differences in drug form, type, preparation and administration practices (Ciccarone et al., 2016; Ciccarone and Harris, 2015; Public Health England, 2019b). Although previous studies have examined the risks and associations with SSTI, using a range of time frames and measures, none have compared data from surveys which, when analysed together, provide both wide geographical coverage and in-depth examination of SSTI. In this analysis we combine data from two separate studies; one an in-depth survey exploring injecting practices and other factors associated with SSTI among PWID in London and the other, a larger bio-behavioural surveillance study of infections and harms among PWID across England, Wales and Northern Ireland. Our analysis was undertaken primarily to assess the generalisability of the in-depth survey findings to the wider population of PWID, but also to explore the similarities and differences in the factors associated with SSTI among PWID when their occurrence is measured over different times frames (lifetime and recently) so as to improve our understanding of the key associations. Considering the multiple recent outbreaks of SSTI in PWID mentioned above, our integrated analysis of both datasets is timely; facilitating an in-depth exploration of factors associated with SSTI and their prevalence to inform implementation of populationspecific interventions.

\section{Materials \& methods}

\subsection{Study sample recruitment and eligibility}

Anonymised data from two distinct surveys were used; 1) The Unlinked Anonymous Monitoring (UAM) Survey of PWID and 2) The Care and Prevent Study ('Promoting skin and soft tissue infection care and preventing AA amyloidosis renal failure among people who inject drugs in the United Kingdom: a mixed-methods multi-phase study'). Methodological details for both have been previously published (Harris et al., 2018; Hope et al., 2014a; Public Health England, 2019c).

The UAM survey recruits PWID through a reflective sentinel sample of specialist services for PWID, such as needle/syringe programmes or addiction treatment centres (these services are widely provided throughout the UK), throughout England, Wales and Northern Ireland. Service users aged 18 and older, who have ever injected drugs, are eligible to participate annually in this surveillance study and those who agree to take part are offered an acknowledgement as well as a $£ 4$ voucher in compensation ( $£ 5$ within London). Participants provide a dried-blood spot sample, which is tested for antibodies against HIV, hepatitis B and hepatitis C (HCV), and for HCV RNA, and self-complete a short questionnaire which includes a single question on the symptoms of an SSTI (a swelling containing pus (abscess), sore or open wound) at an injecting site in the previous year. The UAM survey has approval from Public Health England and the London Research Ethics Committee (98/2/051). Analysis was limited to data from the 2017 and 2018 surveys for respondents who reported injecting during the past year and who had answered questions on SSTI symptoms ( $=2,874)$. Those who had not injected in the past year, and those who took part in 2018 who had already participated in the survey in 2017 were excluded (i.e. duplicates were excluded by only including the first participation in the two-year period, with repeats identified through reported year of last participation).

Survey data from the Care and Prevent (C\&P) Study, which recruited participants from drug treatment centres, homeless hostels and outreach services across London, were used. People were eligible to participate in the survey if they had ever injected psychoactive drugs, were aged 18 and over, and were assessed as able to provide informed consent. Those who agreed to participate completed a detailed researcher-administered, computer-assisted survey focused on SSTI and provided a urine sample for proteinuria urinalysis. Ethical approvals were obtained from the London Bridge Research Ethics Committee [17/ LO/0872] and the LSHTM Observational Research Ethics Committee [12021]. Survey participants received a $£ 10$ voucher as reimbursement for their time. In total, 455 PWID completed the survey between October 2017 and March 2019. Participants were asked to identify if they had ever had a SSTI and were provided with photographs of mild, moderate and severe abscesses, cellulitis and leg ulcers to aid their recall, ensure correct SSTI identification and provide a comparative measure to assess SSTI severity. In addition, participants were asked to self-report whether they had ever been diagnosed with HCV. Both surveys collected similar or identical data on drug-use, injecting practices, sociodemographic characteristics and healthcare use. As the C\&P survey asked about lifetime prevalence of SSTI, data analysis was not restricted to those who reported injecting in the previous year and included the entire sample of PWID.

The possibility of someone participating in both studies is very low due to very limited overlap in the locations used for recruitment recruited. The majority ( $87 \%$ ) of UAM survey recruitment sites were located outside of London, whereas all C\&P recruitment sites were located in London. Although both surveys recruited participants in London, recruitment sites were focused in different areas and utilised different services.

\subsection{Analytical methods}

Demographic and background characteristics of both samples were compared using descriptive statistics. Both univariable and multivariable logistic regression models were used to investigate the crude and adjusted associations of demographic variables and factors associated with SSTI, respectively. We present estimates of odds ratios (OR), $95 \%$ confidence intervals and tests of significance for each variable of interest. Multivariable regression models were built using a manual forward stepwise selection process to build separate models for each dataset to identify the factors associated with reporting SSTI. As opposed to a single combined model, two separate models were built to allow for flexibility and variability of different correlates in each dataset. Shortlisting for inclusion in the multivariable models was 
dependent on where there was evidence of an independent association with the outcome (LRT p-value $\leq 0.05$ in the UAM survey and $\leq 0.1$ in the C\&P survey) and/or a suggested confounding effect from the minimally adjusted models. Since a test for confounding does not exist, an arbitrary $\geq 10 \%$ difference in adjusted ORs was used as the definition of confounding in these analyses. All shortlisted variables were iteratively inserted into the a priori model (which included age, and gender). Following insertion, each variable's impact on the crude OR of all other factors already built into the model was assessed to identify confounding. Likelihood Ratio Tests (LRTs) were also performed to assess the variable's contribution to the model as an independent risk factor. At each forward step, retention in the model was dependent on the factor having the largest confounding effect or strongest evidence of being an independent risk factor. Assessment for multicollinearity in both models was performed through the comparison of the standard errors (SEs) of coefficients on the log scale to those of the unadjusted models. Variables which showed an increase of $>10 \%$ were further investigated and individually removed to assess the nature of collinearity. Provided there was no a priori reason for its inclusion, identified collinearity between pairs was controlled for by removing the variables with the least confounding effect and the greatest change in SE from the model.

\section{Results}

The characteristics of both samples were broadly similar. Both populations were skewed with respect to age, with $68 \%$ and $57 \%$ of participants aged 35 years or more in the UAM survey and the C\&P survey, respectively, and more than two-thirds of participants identified as male in both studies (71 \% in UAM and $75 \%$ in C\&P). Homelessness was common in both samples, with $78 \%$ of the C\&P study sample reporting a history of street homelessness and $50 \%$ of participants from the UAM survey reporting homelessness (both street and hostels) in the past year. Testing of DBS samples collected in the UAM survey found 27 $\%$ had previously been infected with HCV (antibody positive and RNA negative) and $29 \%$ were currently infected with HCV (antibody and RNA positive). Higher prevalence of HIV was found in UAM participants recruited in London (6.4\%) than in the overall sample (1.3\%). In C\&P, $54 \%$ of participants self-reported a previous HCV diagnosis and $5.7 \%$ reported a HIV diagnosis, corresponding to higher HIV prevalence in London found in UAM participants.

SSTI prevalence was high in both samples; $52 \%$ of UAM participants reported having a SSTI symptom in the previous year and $65 \%$ of C\&P participants reported an SSTI during their lifetime. In relation to the photographs provided, $33 \%$ of the C\&P participants described their worst SSTI as mild, $41 \%$ as moderate and $26 \%$ as severe. In both studies, SSTI were least often reported in those who had been injecting for less than one year ( $29 \%$ and $28 \%$ in UAM and C\&P, respectively), and they were most commonly reported among those who had made four or more attempts (needle insertions) to achieve a successful injection ( $66 \%$ for UAM, $85 \%$ for C\&P).

Univariable analyses uncovered similar factors associated with SSTI in both surveys. Participants who were aged $35+$ years; had a current or previous HCV infection; reported injecting for three or more years; injected heroin or heroin and crack cocaine in combination; injected into their hands, feet, neck, groin or other body sites other than their arms or legs; and made more than one attempt at achieving an injection (UAM: last injection, C\&P: typical injection), had increased odds of reporting SSTI (Tables 1 and 2).

Following adjustment for potential confounding, we found the following factors were associated with increased odds of reporting SSTI or symptoms of SSTI in both samples: older age; injecting for three or more years; injecting into the hands, feet, neck, groin or other body sites other than their arms or legs; and making more than one attempt at achieving an injection. Sharing of needle/syringes was associated in UAM and reuse of needle/syringes in the C\&P; these practices have
Table 1

Distribution of associated factors and Crude Odds Ratios for SSTIs: UAM Survey, England, Wales and Northern Ireland, 2017-2018.

\begin{tabular}{|c|c|c|c|c|c|}
\hline Variables of Interest & $\mathrm{N}$ & $\begin{array}{l}\text { SSTIs in } \\
\text { past year } \\
(\%)\end{array}$ & OR & $95 \% \mathrm{CI}$ & P-value \\
\hline Total & 2,874 & $1,486(52)$ & - & - & - \\
\hline \multicolumn{6}{|c|}{ Demographics \& General Health } \\
\hline \multicolumn{6}{|l|}{ Age } \\
\hline$<25$ & 89 & $32(36)$ & Ref. & - & \\
\hline $25-34$ & 809 & $412(51)$ & 1.9 & $1.2-2.9$ & \multirow[t]{2}{*}{0.008} \\
\hline $35+$ & 1,946 & $1,020(52)$ & 2.0 & $1.3-3.1$ & \\
\hline \multicolumn{6}{|l|}{ Gender } \\
\hline Male & 2,046 & $1,018(50)$ & Ref. & - & \multirow[t]{2}{*}{0.001} \\
\hline Female & 818 & $461(56)$ & 1.3 & $1.1-1.5$ & \\
\hline \multicolumn{6}{|l|}{ Born in United Kingdom } \\
\hline Yes & 2,667 & $1,379(52)$ & 1.2 & $0.8-1.6$ & \multirow[t]{2}{*}{0.38} \\
\hline No & 172 & $83(48)$ & Ref. & - & \\
\hline \multicolumn{6}{|l|}{ Hepatitis C Test Result } \\
\hline Negative (antibody negative) & 1,182 & $551(47)$ & Ref. & - & \multirow[t]{4}{*}{$<0.001$} \\
\hline $\begin{array}{l}\text { Current Infection (antibody } \\
\text { and RNA positive) }\end{array}$ & 826 & $473(57)$ & 1.5 & $1.3-1.8$ & \\
\hline $\begin{array}{l}\text { Past Infection (antibody } \\
\text { positive, RNA negative) }\end{array}$ & 788 & $427(54)$ & 1.4 & $1.1-1.6$ & \\
\hline Not tested/insufficient sample & 78 & $35(45)$ & 0.9 & $0.6-1.5$ & \\
\hline \multicolumn{6}{|l|}{ HIV Test Result } \\
\hline Negative & 2,837 & $1,465(52)$ & Ref. & - & \multirow[t]{2}{*}{0.64} \\
\hline Positive & 36 & $20(56)$ & 1.2 & $0.6-2.3$ & \\
\hline \multicolumn{6}{|l|}{ Overdosed in past year } \\
\hline No & & $1,092(49)$ & Ref. & - & \multirow[t]{2}{*}{$<0.001$} \\
\hline Yes & 531 & $319(60)$ & 1.6 & $1.3-1.9$ & \\
\hline \multicolumn{6}{|l|}{ Taken Part in Transactional Sex } \\
\hline Never & & $694(47)$ & Ref. & - & \multirow[t]{3}{*}{$<0.001$} \\
\hline Yes, but not in past year & 150 & $84(56)$ & 1.4 & $1.0-2.0$ & \\
\hline Yes, in past year & 147 & $101(68)$ & 2.5 & $1.7-3.6$ & \\
\hline \multicolumn{6}{|l|}{ Homeless (Street or Hostels) } \\
\hline No & 584 & $280(47)$ & Ref. & - & \multirow[t]{3}{*}{0.17} \\
\hline Yes, but not in past year & 833 & $431(52)$ & 1.2 & $0.9-1.4$ & \\
\hline Yes, in past year & 1,410 & $741(53)$ & 1.2 & $1.0-1.1$ & \\
\hline \multicolumn{6}{|l|}{ Ever Imprisoned } \\
\hline No & 880 & $418(48)$ & Ref. & - & \multirow[t]{2}{*}{0.01} \\
\hline Yes & 1,929 & $1,017(52)$ & 1.2 & $1.1-1.5$ & \\
\hline
\end{tabular}

Drug Injection and Preparation

Years injecting

$\begin{array}{lllll}<1 \text { year } & 85 & 25(29) & \text { Ref. } & - \\ 1-3 \text { years } & 188 & 80(43) & 1.8 & 1.0-3.1 \\ 3+ & 2,506 & 1,316(53) & 2.7 & 1.7-4.3\end{array}$

$<0.001$

Main drug Injected in past year

Opiates, Cocaine, Crack and

Combinations

Amphetamine-like drugs $\quad 98 \quad 36$ (37)

Shared spoons for mixing in past month

$\begin{array}{llllll}\text { No } & 1,581 & 791(50) & \text { Ref. } & - & <0.001 \\ \text { Yes } & 626 & 382(61) & 1.6 & 1.3-1.9 & \\ \text { Shared filters in past month } & & & & & \\ \text { No } & 1,624 & 814(50) & \text { Ref. } & - & <0.001 \\ \text { Yes } & 588 & 366(62) & 1.6 & 1.4-2.0 & \end{array}$

$\begin{array}{lllll}\text { Yes } & 588 & 366(62) & 1.6 & 1.4-2.0\end{array}$

Injecting Frequency, Sites and Hygiene

Days injecting in past month 595

$5-9$ days

$10-20$ days

$20+$ days

Ref. -

0.053

$1.3 \quad 1-1.8$

$1.2 \quad 0.9-1.6$

$1.3 \quad 1.1-1.6$

(continued on next page) 
Table 1 (continued)

\begin{tabular}{|c|c|c|c|c|c|}
\hline Variables of Interest & $\mathrm{N}$ & $\begin{array}{l}\text { SSTIs in } \\
\text { past year } \\
(\%)\end{array}$ & OR & $95 \% \mathrm{CI}$ & P-value \\
\hline \multicolumn{6}{|c|}{ Body Sites injected in past month } \\
\hline Arms or Legs only & 783 & $367(47)$ & Ref. & - & \multirow[t]{3}{*}{$<0.001$} \\
\hline Hands or Feet & 447 & $247(55)$ & 1.4 & $1.1-1.8$ & \\
\hline Groin, Neck or Other & 989 & $569(58)$ & 1.5 & $1.3-1.9$ & \\
\hline \multicolumn{6}{|c|}{ Typical Number of attempts to achieve last injection } \\
\hline 1 & 1,157 & $438(38)$ & Ref. & - & \multirow[t]{4}{*}{$<0.001$} \\
\hline 2 & 623 & $341(55)$ & 2.0 & $1.6-2.4$ & \\
\hline 3 & 395 & $255(65)$ & 3.0 & $2.4-3.8$ & \\
\hline $4+$ & 623 & $408(66)$ & 3.1 & $2.5-3.8$ & \\
\hline \multicolumn{6}{|c|}{ Shared Syringes in past year } \\
\hline No & 1,873 & $767(41)$ & Ref. & - & \multirow[t]{2}{*}{$<0.001$} \\
\hline Yes & 429 & 255 (59) & 2.1 & $1.7-2.6$ & \\
\hline
\end{tabular}

Abbreviations: $\mathrm{N}=$ number of individuals; $\mathrm{OR}=$ odds ratio; $\mathrm{CI}=$ confidence interval; Ref $=$ reference group.

Note: Those who reported injecting into their hands or feet could also have injected into their arms or legs and those who reported injecting into their groin or neck, could also have injected into their hands, feet, arms or legs.

been shown to be closely associated (Hope et al., 2014b) and these two measures of equipment reuse both reflect constrained access to sterile needles and syringes. Additional variables were also associated with increased SSTI but were not common to both samples; i.e. having overdosed in the past year; increased number of days injecting in the past month; and receiving income through social welfare, or illicit activities (Table 3). Two variables common to both were associated in one survey but not the other. Main drug injected in past year was associated with SSTI in the UAM, but not significant in C\&P, probably due to the lower power of the C\&P study. The other was HCV status which was associated in C\&P but not the UAM. This is likely to relate to this variable being measured differently, using self-reports of HCV diagnosis in C\&P and laboratory assessment in UAM. There was no evidence of multicollinearity found during our analyses.

\section{Discussion}

Both samples found high prevalence of self-reported SSTI with commonalities in associated factors that indicate that SSTIs are related with venous access issues as well as hygiene. Lifetime prevalence estimates of SSTI from the C\&P study (65\%) were higher than those in Australia (27 \%) and Mexico (46 \%) (Buchanan, 2006; Topp, 2008), but similar to the levels reported in the USA (68 \%) and Ireland (69 \%) (Biswanger, 2000; Maloney, 2010). UAM reported prevalence of SSTI in the previous year (52\%) was higher than comparable studies, with 37 $\%$ the highest reported (to our knowledge) in a sample of 864 PWID from the California, USA (Fink et al., 2013). Multivariable analyses illustrate common associations with SSTI in both surveys: older age; number of years injecting; injecting into the neck and/or groin; making more than one attempt to achieve an injection. And markers of constrained needle and syringe supply (i.e. sharing or reuse).

The association with markers of constrained needle and syringe supply, that is sharing in UAM Survey and reuse in C\&P, highlights the need to improve the provision of needle and syringe programmes (NSPs) in the UK. New sterile injection equipment, and access to other materials such as clean water and swabs, are key to maintain hygienic injection practice, and so to reduce incidence of SSTI (Harris et al., 2020). While NSPs are widely provided throughout the UK, their provision over the last decade has been impacted by austerity with this increasingly focused on community pharmacies with fewer specialist services (Britsh Medical Association, 2018; Local Government Association, 2018). Our data indicates coverage is currently insufficient, and there is also probably inequity in access (Public Health
Table 2

Distribution of associated factors and Crude Odds Ratios for SSTIs: Care and Prevent Study, London, 2018-2019.

\begin{tabular}{|c|c|c|c|c|c|}
\hline Variables of Interest & $\mathrm{N}$ & $\begin{array}{l}\text { Ever } \\
\text { SSTIs (\%) }\end{array}$ & OR & $95 \% \mathrm{CI}$ & P-value \\
\hline Total & 455 & $\begin{array}{l}296 \\
(65.0)\end{array}$ & - & - & - \\
\hline \multicolumn{6}{|c|}{ Demographics \& Sexual Health/Behaviour } \\
\hline \multicolumn{6}{|l|}{ Age } \\
\hline$<25$ & 58 & $26(45)$ & Ref. & - & $<0.001$ \\
\hline $25-34$ & 155 & $82(60)$ & 2.1 & $1.1-3.81 .7-$ & \\
\hline $35+$ & 242 & $188(72)$ & 3.1 & 5.6 & \\
\hline \multicolumn{6}{|l|}{ Gender } \\
\hline Male & 341 & $220(65)$ & Ref. & - & 0.68 \\
\hline Female & 114 & $76(67)$ & 1.1 & $0.7-1.7$ & \\
\hline \multicolumn{6}{|l|}{ Ethnicity } \\
\hline White/White British & 336 & $226(67)$ & 1.5 & $0.9-2.4$ & 0.12 \\
\hline Black/Asian/Mixed/Other & 89 & $52(58)$ & Ref. & - & \\
\hline \multicolumn{6}{|l|}{ Diagnosed Hepatitis C } \\
\hline Yes & 244 & $191(78)$ & 3.6 & $2.4-5.5$ & $<0.001$ \\
\hline No & 211 & $105(50)$ & Ref. & - & \\
\hline \multicolumn{6}{|l|}{ Diagnosed HIV } \\
\hline Yes & 26 & $15(57.7)$ & 0.7 & $0.3-1.6$ & 0.42 \\
\hline No & 429 & $\begin{array}{l}281 \\
(65.5)\end{array}$ & Ref. & - & \\
\hline \multicolumn{6}{|l|}{ Ever Street Homeless } \\
\hline Yes & 355 & $234(66)$ & 1.2 & $0.8-1.9$ & 0.47 \\
\hline No & 100 & $62(62)$ & Ref. & - & \\
\hline \multicolumn{6}{|l|}{ Main Income Source } \\
\hline $\begin{array}{l}\text { Regular/Temporary Job/ } \\
\text { Family Support }\end{array}$ & 44 & $22(50)$ & Ref. & - & 0.03 \\
\hline $\begin{array}{l}\text { Social Welfare/Illicit } \\
\text { Activities/Other }\end{array}$ & 386 & $257(67)$ & 2.0 & $1.1-3.7$ & \\
\hline \multicolumn{6}{|c|}{ Drug Injection and Preparation } \\
\hline One year or less & 57 & $16(28)$ & Ref. & - & $<0.001$ \\
\hline $2-4$ years & 70 & $33(47)$ & 2.3 & $1.1-4.8$ & \\
\hline $4+$ years & 328 & $247(75)$ & 7.8 & $4.2-14$ & \\
\hline \multicolumn{6}{|c|}{ Main Drugs Injected in past year } \\
\hline $\begin{array}{l}\text { Opiates, Cocaine, Crack and } \\
\text { Combinations }\end{array}$ & 266 & $184(69)$ & 2.5 & $0.9-6.8$ & 0.07 \\
\hline Amphetamine-like drugs & 17 & $8(47)$ & Ref. & - & \\
\hline \multicolumn{6}{|l|}{ Ever Re-use Filters } \\
\hline No, Never/Yes, Occasionally & 346 & $221(64)$ & Ref. & - & 0.01 \\
\hline Yes, Often & 89 & $70(79)$ & 2.1 & $1.2-3.6$ & \\
\hline \multicolumn{6}{|l|}{ Main Dissolvent in past year } \\
\hline Citric Acid & 237 & $162(68)$ & 1.0 & $0.5-2.0$ & 0.98 \\
\hline Other & 44 & $30(68)$ & Ref. & - & \\
\hline
\end{tabular}

Injecting Frequency, Sites and Hygiene

Typical Injecting Frequency

$\begin{array}{lllll}\text { Once per week } & 57 & 25(44) & \text { Ref. } & - \\ 2-7 \text { times per week } & 125 & 78(62) & 2.1 & 1.1-4.0 \\ >\text { once a day } & 273 & 193(71) & 3.1 & 1.7-5.5\end{array}$

$<0.001$

Most common Body Site Injected in past year

$\begin{array}{lllll}\text { Arms or Legs } & 88 & 17(19) & \text { Ref. } & - \\ \text { Hands or Feet } & 115 & 77(67) & 8.5 & 4.4-16\end{array}$

Neck, Groin or Other $\quad 252 \quad 202(80) \quad 16 \quad 9.1-31$

Typical Number of attempts to achieve typical injection

$1202101(50) \quad$ Ref. - $\quad<0.001$

$2 \quad 82 \quad 57(70) \quad 2.3 \quad 1.3-3.9$

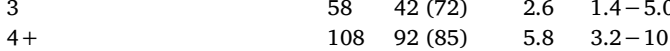

Typical injection-type 
Table 2 (continued)

\begin{tabular}{|c|c|c|c|c|c|}
\hline Variables of Interest & $\mathrm{N}$ & $\begin{array}{l}\text { Ever } \\
\text { SSTIs (\%) }\end{array}$ & OR & $95 \% \mathrm{CI}$ & P-value \\
\hline Venous & 438 & $284(64)$ & Ref. & - & 0.62 \\
\hline Intramuscular/Subcutaneous & 17 & $12(71)$ & 1.3 & $0.5-3.8$ & \\
\hline \multicolumn{6}{|c|}{ Typically Wash Hands Before Injecting } \\
\hline Never/Sometimes & 321 & $213(66)$ & 1.2 & $0.8-1.8$ & 0.37 \\
\hline Always & 134 & $83(62)$ & Ref. & - & \\
\hline \multicolumn{6}{|c|}{ Typically Wipe Skin with Alcohol before Injecting } \\
\hline Never/Sometimes & 248 & $168(67)$ & 1.3 & $0.9-1.9$ & 0.19 \\
\hline Always & 207 & $128(62)$ & Ref. & - & \\
\hline \multicolumn{6}{|l|}{ Ever Reuse Needles/Syringes } \\
\hline Always & 149 & $40(78)$ & 4.1 & $2.0-8.6$ & $<0.001$ \\
\hline Sometimes & 255 & $186(73)$ & 3.0 & $2.0-4.7$ & \\
\hline Never & 51 & $70(47)$ & Ref. & - & \\
\hline
\end{tabular}

Abbreviations: $\mathrm{N}$ = number of individuals; $\mathrm{OR}=$ odds ratio; $\mathrm{CI}=$ confidence interval; Ref $=$ reference group.

England, 2019d); NSP provision urgently needs to be improved.

Age and length of time injecting are highly correlated with each other (Dwyer et al., 2009; Fink et al., 2013; Hope et al., 2008; Tempalski et al., 2013). The association of SSTI occurrence with age is therefore likely to reflect the impact of long-term injecting and in particular, the hardening/narrowing of veins (venous sclerosis), which often occurs after injecting for many years (Maliphant and Scott, 2005). Difficulty injecting into sclerotic veins can lead to unintentional subcutaneous injection (or 'missed hits') (Rhodes et al., 2007) and require an increased number of attempts to achieve an injection. Difficulty accessing peripheral veins also precipitates transitions to more risky injection sites, such as the femoral vein in the groin or the jugular vein in the neck (Ciccarone and Harris, 2015; Darke et al., 2001). In both samples, a high proportion of participants reported injecting into the femoral or jugular vein in the past year (UAM: $45 \%$; C\&P: $55 \%$ ) and making four or more attempts before achieving an injection (UAM; 22 $\%$, C\&P: $24 \%$ ). As reported in previous studies, our analysis produced strong multivariable associations between SSTI, multiple injection attempts and injecting in the femoral or jugular vein (Harris and Rhodes, 2012; Hope et al., 2017). It is also possible that there is an element of reverse causality at play, as transitioning to these other body sites and higher numbers of missed injections may be a result of SSTI already present in the arms or legs.

In both samples, and in accordance with the literature, women more often reported an SSTI than men, however, due to limited power, the association was not significant in the C\&P sample and was thus not listed as an association found in both surveys (Fink et al., 2013; Hope et al., 2008; Lloyd-Smith et al., 2005; Spijkerman et al., 1996). Increased susceptibility to risk is likely due to an interplay of physical and social factors. Women may experience loss of peripheral venous viability earlier in their injecting trajectory than men, due to a finer venous structure (Huxley, 2007). Difficult venous access, as previously stated, can precipitate unintentional and intentional subcutaneous injection as well as transitions to deeper veins, such as the jugular and femoral veins, injection into which carries a greater infection risk (Lloyd-Smith, 2009; Topp, 2008). Women are particularly vulnerable to adverse consequences of identification as a person who injects drugs (such as loss of children, family support and/or sex-work income) and may transition early to injecting into less visible sites such as the groin (Harris and Rhodes, 2013). Gendered power dynamics can exacerbate risk of unsafe injecting, with women more likely than men to have limited control over drug purchase, injection equipment supply, drug injection preparation or administration (Hope et al., 2010; Morris et al., 2018). This can increase the likelihood of receiving injecting assistance and using injecting equipment after others (Wood, 2003). Sex work is
Table 3

Adjusted Odds Ratios of associated factors for SSTIs: Both Datasets.

\begin{tabular}{|c|c|c|c|c|c|c|}
\hline \multirow{2}{*}{$\begin{array}{l}\text { Variables in } \\
\text { Multivariable Model }\end{array}$} & \multicolumn{3}{|c|}{ UAM Survey } & \multicolumn{3}{|c|}{ Care \& Prevent Study } \\
\hline & AOR & $(95 \% \mathrm{CI})$ & LRT & AOR & $(95 \% \mathrm{CI})$ & LRT \\
\hline \multicolumn{7}{|c|}{ Demographic \& Health Variables } \\
\hline \multicolumn{7}{|c|}{ Age } \\
\hline$<25$ & Ref. & - & $<0.001$ & Ref. & - & 0.02 \\
\hline $25-34$ & 3.9 & $1.7-8.9$ & & 2.2 & $1.0-5.2$ & \\
\hline $35+$ & 4.4 & $2.0-10.0$ & & 3.2 & $1.4-7.1$ & \\
\hline Gender & & & & & & 0.10 \\
\hline Male & Ref. & - & 0.01 & Ref. & - & \\
\hline Female & 1.4 & $1.1-1.7$ & & 1.4 & $0.8-2.6$ & \\
\hline \multicolumn{7}{|l|}{$\begin{array}{l}\text { Overdosed in past } \\
\text { year }\end{array}$} \\
\hline No & Ref. & - & 0.003 & & $\Phi$ & \\
\hline Yes & 1.5 & $1.2-2.0$ & & & & \\
\hline $\begin{array}{l}\text { Diagnosed } \\
\text { Hepatitis C }\end{array}$ & & & & & & 0.002 \\
\hline No & & $\pi$ & & Ref. & - & \\
\hline Yes & & & & 2.2 & $1.3-3.7$ & \\
\hline $\begin{array}{l}\text { Main Income } \\
\text { Source }\end{array}$ & & & & & & 0.05 \\
\hline $\begin{array}{l}\text { Regular Job/ } \\
\text { Temporary } \\
\text { Work/Family } \\
\text { Support }\end{array}$ & & $\Phi$ & & Ref. & - & \\
\hline $\begin{array}{c}\text { Social Welfare/ } \\
\text { Other/Illicit } \\
\text { Activities }\end{array}$ & & & & 2.2 & $1.0-4.9$ & \\
\hline
\end{tabular}

Drug Injection and Preparation Variables

Years injecting

$<1$ year

$1-3$ years

$3+$

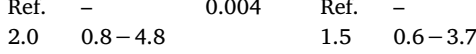

Main Drug Injected

in past year

Amphetamine-like

Opiates, Cocaine,

Crack and

Combinations

$\begin{array}{llll}3.0 & 1.4-6.5 & 1.5 & 0.6-3.7 \\ & & 2.2 & 1.0-4.9\end{array}$

0.10

$\begin{array}{ll}\text { Ref. } & - \\ 1.7 & 1.1-2.8\end{array}$

0.04

๘

Injecting Frequency, Sites and Hygiene Variables

Main Injection Site

on Body in past year

Arms or Legs

Ref. -

Neck, Groin or Other $\quad 1.6 \quad 1.2-2.3$

Typical Number of

attempts to

achieve

injection

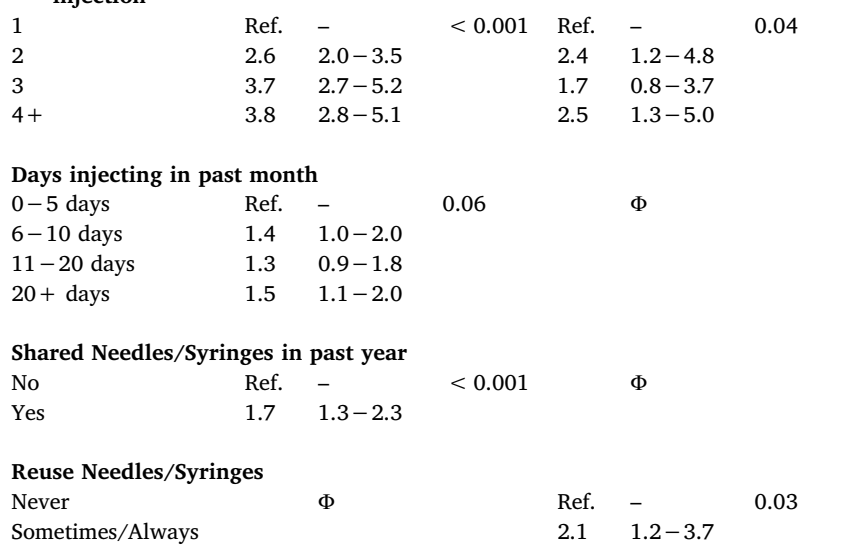

Sometimes/Always
$<0.001$ Ref. -

$6.2 \quad 2.9-13$

$10 \quad 4.9-20$

$<0.001$
$\boldsymbol{\Phi}$ Variable was not asked in the survey. $\boldsymbol{\varpi}$ Variable was asked but was not significant in the final model. Abbreviations: $\mathrm{N}=$ number of individuals; AOR $=$ adjusted odds ratio; $\mathrm{CI}=$ confidence interval; LRT $=$ likelihood ratio test $\mathrm{p}$ value; Ref = reference group. Note: In the UAM study, questions based on practices in the past month included a level with those who did not inject in the past month in order to retain the full set of observations for multivariable 5 analysis. 
more likely to be a viable income-generation avenue for women who inject drugs. Sex work among women is associated with more frequent injecting, and therefore SSTI risk (Kerr et al., 2016). However, as sex work may be undertaken to financially support high levels of injecting (Morris et al., 2018) it is spurious to imply a causal link.

The majority of participants in both samples report injecting heroin or a heroin/crack cocaine combination. Amphetamine or sole injection of powder cocaine was relatively rare. Preparation of heroin and/or crack cocaine for injection in the UK, requires use of an acidifier with water to render these base drugs into an injectable solution. The C\&P study has previously shown that overuse of an acidifier for injection was common, with $30 \%$ using a whole sachet of acid or more (Harris et al., 2019). There is a likely causal pathway between acidifier overuse and venous damage, which in turn precipitates SSTI risk (Ciccarone and Harris, 2015; Harris et al., 2019). Amphetamine-like drugs, with limited SSTI risk, are water-soluble and do not need to be prepared using an acid (Ciccarone, 2011).

The substantial similarity of the associations with factors related to venous damage in both samples, such as numerous repeat injection attempts, reinforced the significance of these factors in influencing SSTI development and the need for interventions addressing venous health (Harris et al., 2019). High comparability of associations in both samples strengthen their generalizability across the UK and so our confidence in understanding the factors associated with SSTI that impact PWID.

The association between SSTI and repeat injection attempts something that may be easy for services to ask about - suggests a possible avenue for identification of those with vascular access problems and/or poor injection technique for the offer of interventions. Interventions offered should address, besides general injection hygiene, the importance of vein health and include advice to improve this, e.g. to reduce acid use, rotate injection sites, and recommendations to reduce the number of injection attempts.

\subsection{Limitations}

Although the sample size of the UAM Survey was larger than C\&P, both were adequately powered. However, the smaller C\&P study sample and the differences in a number of the questions asked prevented a combined analysis approach. Both data sources may be subject to reporting bias as self- reports of SSTI symptoms were used, although this was minimised in the C\&P study, which used photos of typical symptoms in the survey. However, previous studies have indicated that self- reporting of SSTI is a reliable method to establish prevalence (Morrison et al., 1997). As we used data from cross-sectional studies, we were not able to investigate temporal relationships between factors associated with and SSTI and indeed we could not eliminate the possibility of reverse causality. Systemic differences in questions asked between surveys limited interpretation and thus require caution when being compared. Finally, we cannot exclude the possibility of participant duplication between both studies, although, as addressed in the methods, this is unlikely.

\subsection{Conclusion}

The results of this study highlight a high prevalence of SSTI amongst PWID in the UK. Injecting- related SSTI are largely preventable, yet are a significant burden, both in terms of the suffering experienced by PWID and economic and health system costs. Together, our two datasets provide strong evidence of an association between difficulties with venous access and SSTI occurrence and reiterate the importance of providing easy access to the materials needed for hygienic injection. A high proportion of respondents in both samples required multiple attempts to achieve an injection and transitions to injecting in deep veins, such as the femoral, were also common. There is a clear need to attend to the underlying causes of venous damage among PWID in the UK. As detailed elsewhere (Harris et al., 2019) overuse of acidifiers is a potentially modifiable risk factor. Asking about repeat injection attempts may be an easy to use approach for health services to identify those with vascular access problems and/or poor injection technique and so offer targeted interventions. Interventions should address, besides general injection hygiene, the importance of vein health, including advice on how to improve this.

\section{Author contribution}

The study was conceived by MH, VH and EH. UAM data collection tools were developed by $\mathrm{VH}$ and $\mathrm{MH}$. UAM data collection was overseen by EH, CE and KS. UAM data management and cleaning was conducted by $\mathrm{EH}$ and CE. C\&P data collection tools were developed by MH. C\&P data collection was overseen by $\mathrm{MH}$ and TW. Data analysis for both surveys was conducted by JD, with input from $\mathrm{EH}, \mathrm{TW}, \mathrm{MH}$ and $\mathrm{VH}$. The paper was drafted by JD with substantial input from $\mathrm{MH}$, EH and VH. All authors read and commented on the final manuscript.

\section{Role of funding source}

Magdalena Harris was funded by a National Institute for Health Research (NIHR) Career Development Fellowship [CDF-2016-09-014] for the Care \& Prevent Study. The UAM survey was core funded by Public Health England. The views expressed are those of the authors and not necessarily those of the NHS, the NIHR or the Department of Health and Social Care.

\section{Declaration of Competing Interest}

No conflict declared.

\section{Acknowledgement}

Care \& Prevent study collaborators Jenny Scott and Dan Ciccarone, C\&P and UAM study sites and participants.

\section{Appendix A. Supplementary data}

Supplementary material related to this article can be found, in the online version, at doi:https://doi.org/10.1016/j.drugalcdep.2020, 108080 .

\section{References}

Biswanger, I., 2000. High prevalence of abscesses and cellulitis among community-recruited injection drug users in San Francisco. Clin. Infect. Dis. 30.

Boucher, L., Marshall, Z., Larose-Hebert, K., Flynn, J., Kendall, C., 2017. Expanding conceptualizations of harm reduction: results from a qualitative community-based participatory research study with people who inject drugs. Harm Reduct. J. 14.

Britsh Medical Association, 2018. Feeling the Squeeze: the Local Impact of Cuts to Public Health Budgets in England.

Buchanan, D., 2006. Demographic, HIV risk behavior, and health status characteristics of "crack" cocaine injectors compared to other injection drug users in three New England cities. Drug Alcohol Depend. 81, 221-229.

Bundle, N., Bubba, L., Coelho, J., Kwiatkowska, R., Cloke, R., King, S., 2017. Ongoing outbreak of invasive and non-invasive disease due to group A Streptococcus (GAS) type emm66 among homeless and people who inject drugs in England and Wales, January to December 2016. Euro Surveill. 22.

Ciccarone, D., 2011. Stimulant abuse: pharmacology, cocaine, methamphetamine, treatment, attempts at pharmacotherapy. Prim. Care 38, 41-58.

Ciccarone, D., Harris, M., 2015. Fire in the vein: heroin acidity and its proximal effect on users' health. Int. J. Drug Policy 26, 1103-1110.

Ciccarone, D., Unick, G., Cohen, J., 2016. Nationwide increase in hospitalizations for heroin-related soft tissue infections: associations with structural market conditions. Drug Alcohol Depend. 163, 126-133.

Darke, S., Ross, J., Kaye, S., 2001. Physical injecting sites among injecting drug users in Sydney, Australia. Drug Alcohol Depend. 62, 77-82.

del Giudice, P., 2004. Cutaneous complications of intravenous drug abuse. Br. J. Dermatol. 150, 1-10.

Dwyer, R., Topp, L., Maher, L., 2009. Prevalence and correlates of non-viral injecting related injuries and diseases in a convenience sample of Australian injecting drug users. Drug Alcohol Depend. 100, 9-16. 
Fink, D., Lindsay, S., Slymen, D., Kral, A., 2013. Abscess and self-treatment among injection drug users at four California syringe exchanges and their surrounding communities. Subst. Use Misuse 48, 523-531.

Gilbert, A., Hellman, J., Wilkes, M., Vaughan, W., 2019. Self-care habits among people who inject drugs with skin and soft tissue infections: a qualitative analysis. Harm Reduct. J. 16.

Harris, M., Rhodes, T., 2012. Venous access and care: harnessing pragmatics in harm reduction for people who inject drugs. Addiction 107, 1090-1096.

Harris, M., Rhodes, T., 2013. Hepatitis C treatment access and uptake for people who inject drugs: a review mapping the role of social factors. Harm Reduct. J. 10.

Harris, M., Brathwaite, R., McGowan, C.R., Ciccarone, D., Gilchrist, G., McCusker, M., O’Brien, K., Dunn, J., Scott, J., Hope, V., 2018. "Care and prevent": rationale for investigating skin and soft tissue infections and AA amyloidosis among people who inject drugs in London. Harm Reduct. J. 15, 15-17. https://doi.org/10.1186/s12954018-0233-y.

Harris, M., Scott, J., Wright, T., Ciccarone, D., Hope, V., 2019. Injecting related health harms and overuse of acidifiers among people who inject heroin and crack cocaine in London: a mixed methods study. Harm Reduct. J. 1.

Harris, M., Scott, J., Hope, V., Wright, T., McGowan, C., Ciccarone, D., 2020. Navigating environmental constraints to injection preparation: the use of saliva and other alternatives to sterile water among unstably housed PWID in London. Harm Reduct. J. 17.

Hope, V., 2010. Neglected Infections, Real Harms: a Global Scoping of Injection-Related Bacterial Infections and Responses.

Hope, V., Kimber, J., Vickerman, P., Hickman, M., Ncube, F., 2008. Frequency, factors and costs associated with injection site infections: findings from a national multi-site survey of injecting drug users in England. BMC Infect. Dis. 8, 1-8. https://doi.org/10. 1186/1471-2334-8-120.

Hope, V., Marongiu, A., Parry, J., Ncube, F., 2010. The extent of injection site infection in injecting drug users: findings from a national surveillance study. Epidemiol. Infect. 138, 1510-1518.

Hope, V., Cullen, K., Croxford, S., Parry, J., Ncube, F., 2014a. Factors associated with the use of cleaned needles and syringes among people who inject drugs in the UK: who should we target to minimise the risks? Int. J. Drug Policy 25, 924-927.

Hope, V., Harris, J.R., Angelis De, D., 2014b. Two decades of successes and failures in controlling the transmission of HIV through injecting drug use in England and Wales, 1990 to 2011. Euro Surveill. 19.

Hope, V., Iversen, J., Cullen, K., 2017. Injection into the jugular vein among people who inject drugs in the United Kingdom: prevalence, associated factors and harms. Int. J. Drug Policy 46, 28-33.

Huxley, V., 2007. Sex and the cardiovascular system: the intriguing tale of how women and men regulate cardiovascular function differently. Adv. Physiol. Educ. 31, 17-22.

Kerr, T., Shannon, K., Strathdee, S., Hayashi, K., 2016. Sex work and HIV incidence among people who inject drugs. AIDS 30.

Kwiatkowska, R., Manley, P., Sims, B., Lamagni, T., Ready, D., 2018. Outbreak of group A Streptococcus emm94.0 affecting people who inject drugs in southwest England, April 2017. Am. J. Infect. Control 46, 238-240.

Larney, S., Peacock, A., Mathers, B.M., Hickman, M., Degenhardt, L., 2017. A systematic review of injecting-related injury and disease among people who inject drugs. Drug Alcohol Depend. 171, 39-49.

Lewer, D., Harris, M., Hope, V., 2017. Opiate injection-associated skin, soft tissue, and vascular infections, England, UK, 1997-2016. Emerg. Infect. Dis. 23.

Lloyd-Smith, E., 2009. The Epidemiology of Cutaneous Injection-Related Infections among Injection Drug Users at a Supervised Injection Facility.

Lloyd-Smith, E., Kerr, T., Hogg, R.S., Li, K., Montaner, J.S.G., Wood, E., 2005. Prevalence and correlates of abscesses among a cohort of injection drug users. Harm Reduct. J. 2,
1-4. https://doi.org/10.1186/1477-7517-2-24.

Local Government Association, 2018. Local Government Funding: Moving the Conversation on.

Maliphant, J., Scott, J., 2005. Use of the femoral vein ('groin injecting') by a sample of needle exchange clients in Bristol, UK. Harm Reduct. J. 2.

Maloney, S., 2010. What are the risk factors for soft tissue abscess development among injecting drug users? Nurs. Times 106.

Marks, M., Pollock, E., Armstrong, M., Morris-Jones, S., Kidd, M., Gothard, P., 2013. Needles and the damage done: reasons for admission and financial costs associated with injecting drug use in a Central London Teaching Hospital. J. Infect. 66, 95-102.

Miller Lloyd, L., Landry, J., Macmadu, A., Allard, I., Waxman, M., 2020. Barriers to healthcare for people who inject drugs: a survey at a syringe exchange program. Subst. Use Misuse 55 (6), 896-899.

Morris, M., Montgomery, M., Briceno, A., Evans, J., 2018. A study of sexual relationship power among young women who inject drugs and their sexual partners. Subst. Use Misuse 53, 1281-1287.

Morrison, A., Elliot, L., Gruer, L., 1997. Injecting-related harm and treatment seeking behaviour among injecting drug users. Addiction 92, 1349-1352.

Neale, J., Tompkins, C., Sheard, L., 2008. Barriers to accessing generic health and social care services: a qualitative study of injecting drug users. Health Soc. Care Community $16,147-154$.

Packer, S., Pichon, B., Thompson, S., Neale, J., Njoroge, J., Kwiatkowska, R., 2019. Clonal expansion of community-associated meticillin-resistant Staphylococcus aureus (MRSA) in people who inject drugs (PWID): prevalence, risk factors and molecular epidemiology, Bristol, United Kingdom, 2012 to 2017. Euro Surveill. 24.

Public Health England, 2019a. Shooting up: Infections among People who Inject Drugs in the UK, 2019.

Public Health England, 2019b. Unlinked Anonymous Monitoring Survey of People who Inject Drugs: Data Tables.

Public Health England, 2019c. Unlinked Anonymous Monitoring (UAM) Survey of HIV and Viral Hepatitis among PWID: 2019 Report.

Public Health England, 2019d. Hepatitis C in the UK 2019: Working to Eliminate Hepatitis C as a Major Public Health Threat.

Rhodes, T., Briggs, D., Kimber, J., 2007. Crack-heroin speedball injection and its implications for vein care: qualitative study. Addiction 102, 1782-1790.

Roose, R., 2009. Self-management of injection-related wounds among injecting drug users. J. Addict. Dis. 28, 74-80.

Salmon, A., 2009. Injecting-related injury and disease among clients of a supervised injecting facility. Drug Alcohol Depend. 101, 132-136.

Spijkerman, I., van Ameijden, E., Mientjes, G., 1996. HIV infection and other risk factors for skin abscesses and endocarditis among injection drug users. J. Clin. Epidemiol. 49.

Tempalski, B., Pouget, E., Clenand, C., 2013. Trends in the population prevalence of people who inject drugs in US metropolitan areas 1992-2007. PLoS One 8.

Tookes, H., Diaz, C., Li, H., Khalid, R., Doblecki-Lewis, S., 2015. A cost analysis of hospitalizations for infections related to injection drug use at a county safety-net hospital in Miami, Florida. PLoS One 10.

Topp, L., 2008. Prevalence and predictors of injecting-related injury and disease among clients of Australia's needle and syringe programs. Aust. N. Z. J. Public Health 32, 34-37.

UNAIDS, 2017. 9090 90: An Ambitious Treatment Target to Help End the AIDS Epidemic.

Wood, E., 2003. Requiring help injecting as a risk factor for HIV infection in the Vancouver epidemic: implications for HIV prevention. Can. J. Public Health 94, 355-359.

World Health Organisation, 2016. Global Health Sector Strategy on Viral Hepatitis. 2016-2021. 